\title{
Acute fatty liver of pregnancy
}

\author{
Hin Hin Ko BSc Pharm MD, Eric Yoshida MD MHSc FRCPC
}

HH Ko, E Yoshida. Acute fatty liver of pregnancy. Can J Gastroenterol 2006;20(1):25-30.

Acute fatty liver of pregnancy (AFLP) is a rare, potentially fatal complication that occurs in the third trimester or early postpartum period. Although the exact pathogenesis is unknown, this disease has been linked to an abnormality in fetal fatty acid metabolism. Early diagnosis of AFLP sometimes can be difficult because it shares features with other common conditions such as pre-eclampsia, viral hepatitis and cholestasis of pregnancy. However, a careful history and physical examination, in conjunction with compatible laboratory and imaging results, are often sufficient to make the diagnosis, and liver biopsy is rarely indicated. Supportive care and expeditious delivery are essential to optimal maternal-fetal outcomes and remain as the mainstay treatment for AFLP.

Key Words: Fatty; Liver; Pregnancy

A cute fatty liver of pregnancy (AFLP) is an uncommon but potentially fatal complication that occurs in the third trimester or early postpartum period. It was first described in 1940 by Sheehan (1) as an "acute yellow atrophy of the liver". AFLP is characterized by microvesicular fatty infiltration of hepatocytes without any inflammation or necrosis. It has an incidence of approximately one in 10,000 to 15,000 pregnancies (2). In the past, maternal and perinatal mortality were reported to be as high as $75 \%$ and $85 \%$, respectively (3). More current data showed that with prompt diagnosis and treatment, the maternal and perinatal mortality have greatly decreased, to approximately $18 \%$ and $23 \%$, respectively $(1,4,5)$. Despite the accumulation of data about this condition, the exact pathogenesis has yet to be determined. At present, supportive care and expeditious delivery remain the best treatment. The present article provides a review of AFLP, including etiology, pathophysiology, clinical presentations, diagnosis and management.

\section{CLINICAL PRESENTATION}

The majority of women who are diagnosed with AFLP are in the third trimester of pregnancy and the mean gestational age is 35 to 36 weeks, with a range of 28 to 40 weeks $(5,6)$. Isolated case reports $(1,3,7,8)$ of AFLP have shown that it can occur as early as 26 weeks and as late as the immediate postpartum period. Monga and Katz (9) reported a case diagnosed at 22 weeks gestation. Clinical findings in AFLP vary because it may occur

\section{La stéatose hépatique aiguë gravidique}

La stéatose hépatique aiguë gravidique (SHAG) est une complication rare, potentiellement mortelle, qui se produit au cours du troisième trimestre de la grossesse ou au début du post-partum. Même si on n'en connaît pas bien la pathogenèse, la maladie est liée à une anomalie du métabolisme des acides gras chez le fotus. Le diagnostic précoce de la SHAG est parfois difficile à poser parce que la maladie présente des traits communs avec d'autres affections courantes, notamment la pré-éclampsie, l'hépatite virale et la cholestase gravidique. Toutefois, une anamnèse minutieuse et un examen physique, associés à des résultats d'examens de laboratoire et d'imagerie évocateurs, suffisent souvent à poser le diagnostic, et il est rarement indiqué de procéder à une biopsie du foie. Des soins de soutien et l'accouchement sans délai sont essentiels à la bonne santé de la mère et du fœutus et ils constituent, en fait, le principal traitement de la SHAG. with varying degrees of clinical severity and in conjunction with other third trimester symptoms, making early diagnosis of AFLP difficult. Patients often present with nonspecific symptoms such as anorexia, nausea, vomiting, malaise, fatigue, headache and abdominal pain. On physical examination, the patient is usually febrile and jaundiced, which is very common and eventually occurs in more than $70 \%$ of patients with AFLP as the condition progresses (10). Tenderness in the right upper quadrant or midepigastric area may be present (8). The liver is usually small and nonpalpable. In severe cases, the patient can present with multisystem involvement including acute renal failure, encephalopathy, gastrointestinal bleeding, pancreatitis and coagulopathy. Some women may also have pre-eclampsia as well, with edema and hypertension. It is believed that the hemolysis, elevated liver enzymes and low platelets (HELLP) syndrome, pre-eclampsia, thrombotic thrombocytopenia purpura and AFLP may all be a spectrum of the same illness. Transient diabetes insipidus may also occur, but is very rare $(11,12)$. The prevalence of common signs and symptoms of AFLP is listed in Table 1.

AFLP also has a detrimental effect on the fetus. One of the complications of AFLP is maternal metabolic acidosis secondary to impaired clearance of serum lactate by damaged hepatocytes (13). Maternal metabolic acidosis directly affects fetal acid-base status (14). Therefore, prompt correction of maternal metabolic acidosis is essential to the fetal well-being. Expeditious birth may be necessary. 


\begin{tabular}{lc} 
TABLE 1 \\
Common signs and symptoms of acute fatty liver of \\
pregnancy & Prevalence (\%) \\
\hline Common signs and symptoms & $>70$ \\
\hline Jaundice & $50-60$ \\
Abdominal pain (usually right upper quadrant, & \\
$\quad$ midepigastric or radiating to back) & $60-80$ \\
Central nervous system (altered sensorium, & \\
$\quad$ confusion, disorientation, psychosis, restlessness, & \\
$\quad$ seizures or even coma) & 55 \\
Disseminated intravascular coagulation & $50-60$ \\
Nausea and vomiting & $20-60$ \\
Gastrointestinal bleeding & 50 \\
Acute renal failure & $40-60$ \\
Oliguria & 50 \\
Tachycardia & 50 \\
Late-onset pyrexia & \\
\hline
\end{tabular}

Data from references 7 and 16

\section{LABORATORY FINDINGS}

Table 2 summarizes some of the common laboratory findings of AFLP. Patients will often have an elevated white blood cell count (greater than $15 \times 10^{9} / \mathrm{L}$ ), but a normal hematocrit unless hemorrhage has occurred $(1,14)$. Hemolysis and thrombocytopenia may also be present (15). The prothrombin and partial thromboplastic times are both prolonged, and fibrinogen levels are below normal $(1,14,15)$. Disseminated intravascular coagulopathy occurs when fibrin split products are found $(75 \%$ of patients) (4,16). Abnormalities in liver biochemistry include elevated serum aminotransferases (ie, serum aspartate aminotransferase and alanine aminotransferase) levels of $300 \mathrm{U} / \mathrm{L}$ to $500 \mathrm{U} / \mathrm{L}$, but the range has been reported to be from normal to $1000 \mathrm{U} / \mathrm{L}$ (13). Elevated serum aminotransferases may also be associated with raised serum ammonia, amino acid levels and lactic acidosis, uric acid, hyperbilirubinemia and hypoglycemia secondary to impaired hepatic glycogenolysis (17). Alkaline phosphatase may be elevated up to 10 times normal; however, alkaline phosphatase can also be increased during the third trimester normally (1). Lastly, the blood urea nitrogen and creatinine may also be elevated, and acute renal failure may complicate severe cases $(1,14)$.

\section{DIAGNOSIS}

The diagnosis of AFLP can be challenging because the initial clinical presentation may be nonspecific. The patient's history, clinical features and biochemical abnormalities may mimic conditions such as acute viral hepatitis, pre-eclampsia, HELLP syndrome, intrahepatic cholestasis or others. Because AFLP is uncommon, the best approach to any pregnant women with liver dysfunction is to quickly rule out other, more likely, causes. One of the most common multiorgan diseases of late pregnancy is pre-eclampsia (3). Although women with AFLP can also have pre-eclampsia, patients with pre-eclampsia alone are not usually jaundiced and do not usually have hypoglycemia, as seen in AFLP (7). Furthermore, AFLP often presents more acutely than pre-eclampsia, which can develop over several days or weeks. In addition, pre-eclampsia rarely presents with severe coagulopathy such as disseminated intravascular coagulation. Besides pre-eclampsia, acute viral hepatitis should also
TABLE 2

Summary of laboratory findings in acute fatty liver of pregnancy

\begin{tabular}{lc}
\hline Hematology & Normal \\
Hemoglobin & Normal \\
Hematocrit & $\uparrow$ \\
White blood cells & Normal to $\downarrow$ \\
Platelets & \\
Liver studies & $\uparrow \uparrow$ \\
Aspartate aminotransferase & $\uparrow \uparrow$ \\
Alanine aminotransferase & $\uparrow$ \\
Gamma-glutamyltransferase & $\uparrow \uparrow$ \\
Alkaline phosphatase & Normal initially, then $\downarrow$ \\
Lactate dehydrogenase & $\uparrow \uparrow$ \\
Bilirubin, total & $\uparrow \uparrow$ \\
Bilirubin, direct & $\uparrow$ \\
Ammonia & $\downarrow \downarrow$ \\
Glucose & $\downarrow$ \\
Cholesterol & $\downarrow$ \\
Triglycerides & $\uparrow$ \\
Coagulation studies & $\uparrow$ \\
International normalized ratio & $\uparrow \uparrow$ \\
Partial thromboplastin time & $\uparrow$ \\
Fibrinogen & $\uparrow \uparrow$ \\
Fibrin split products & Present \\
Antithrombin III & $\downarrow \downarrow$ \\
Renal & \\
Uric acid & $\uparrow$ \\
Blood urea nitrogen & $\uparrow$ \\
Creatinine & \\
\hline
\end{tabular}

$\uparrow$ Mildly elevated; $\uparrow \uparrow$ Moderately to markedly elevated; $\downarrow$ Mildly decreased $\downarrow \downarrow$ Moderately to markedly decreased

be ruled out in pregnant women with symptoms of liver dysfunction. In viral hepatitis, patients usually have much higher levels of serum transaminases, with values often well above $1000 \mathrm{U} / \mathrm{L}$, and serology tests will be positive. Moreover, uric acid levels are rarely elevated in fulminant hepatitis and signs of pre-eclampsia are absent in viral hepatitis. Finally, intrahepatic cholestasis of pregnancy can cause jaundice as well; however, it is characterized by intense pruritus and elevated alkaline phosphatase, and is not associated with abdominal pain, nausea, vomiting, liver failure or disseminated intravascular coagulation $(4,18)$. Characteristics of common liver diseases in pregnancy are summarized in Table 3.

Both ultrasound examination and computed tomography may demonstrate fatty infiltration of the liver; however, the sensitivity and specificity of these imaging studies are insufficient to make a definitive diagnosis of AFLP. False negative results are common $(15,19)$. Historically, the necessity of liver biopsy in making the diagnosis of AFLP originated with Ober and Lecompte in 1955 (20) because this condition was clinically indistinguishable from fulminant infectious hepatitis. However, liver biopsy can cause complications in the presence of coagulopathy. Nowadays, serological markers for viral hepatitis and clinical and biochemical findings for AFLP are available, thus, liver biopsy is not mandatory for diagnosis in most cases and clinically is rarely performed (21). Although AFLP 
TABLE 3

Characteristics of common liver diseases in pregnancy

\begin{tabular}{|c|c|c|c|c|c|}
\hline Disease & Trimester & Incidence & Signs and symptoms & Laboratory findings & Complications \\
\hline $\begin{array}{l}\text { Pre-eclampsia } \\
\text { and eclampsia }\end{array}$ & 2 nd or 3 rd & $5 \%$ to $10 \%$ & $\begin{array}{l}\text { Nausea; vomiting; } \\
\text { epigastric pain; edema; } \\
\text { hypertension; mental } \\
\text { status changes; jaundice } \\
\text { (late presentation) }\end{array}$ & $\begin{array}{l}\text { ALT }<500 \text { U/L, proteinuria, } \\
\text { DIC }(7 \%)\end{array}$ & $\begin{array}{l}\text { Maternal: Hypertensive crisis; renal impairment; } \\
\text { hepatic rupture/infarct; neurological } \\
\text { (seizures, cerebrovascular disease) } \\
\text { Fetal: Abruptio placentae; prematurity; } \\
\text { IUGR leading to increased perinatal } \\
\text { morbidity and mortality }\end{array}$ \\
\hline Viral hepatitis & Any & $\begin{array}{l}\text { Same as } \\
\text { general } \\
\text { population }\end{array}$ & $\begin{array}{l}\text { Nausea; vomiting; } \\
\text { fever }\end{array}$ & $\begin{array}{l}\text { ALT greatly elevated } \\
\text { (>500 U/L); elevated bilirubin; } \\
\text { positive serology tests }\end{array}$ & Maternal: Increased mortality with hepatitis E \\
\hline $\begin{array}{l}\text { Drug-induced } \\
\text { hepatitis }\end{array}$ & Any & Unknown & $\begin{array}{l}\text { Usually none; nausea; } \\
\text { vomiting; pruritis; } \\
\text { jaundice (in } \\
\text { cholestatic hepatitis) }\end{array}$ & Variable & Unknown \\
\hline
\end{tabular}

ALP Alkaline phosphatase; ALT Alanine aminotransferase; DIC Disseminated intravascular coagulation; GGT Gammaglutamyl transpeptidase; HELLP Hemolysis, elevated liver enzymes, low platelets; IUGR Intrauterine growth restrictions; LCHAD Long-chain 3-hydroxyacyl-CoA dehydrogenase; LDH Lactate dehydrogenase; PT Prothrombin time

shares features with other, more common, illnesses, a careful history and physical examination, in conjunction with compatible laboratory and imaging results, are often sufficient to make the diagnosis. Liver biopsy should not be performed to confirm a diagnosis of AFLP or to distinguish AFLP from severe pre-eclampsia, because management of both conditions are the same. Vigil-De Gracia and Lavergne (22) suggested that liver biopsy may be justified in cases when liver function does not return to normal postpartum, and in those cases where the definitive diagnosis in the early stages of AFLP is necessary as the primary indication for delivery. Histologically, one will see microvesicular steatosis with sparing of zone 1 . There will be pericentral pallour with lobular disarray and vacuolization of the centrizonal hepatocytes. Special stains, such as oil red $\mathrm{O}$, must be applied to fresh-frozen specimens to demonstrate fat $(4,23)$. There may be patchy hepatocellular necrosis; however, widespread necrosis or inflammation is absent (16).

\section{MANAGEMENT}

Early diagnosis, prompt delivery and intensive supportive care are the cornerstones in the management of AFLP. Because the laboratory findings in AFLP frequently do not reflect the gravity of the problem, a high level of suspicion, with low threshold of admission to monitor, should be taken. If the patients are at high risk for multisystem organ failure and death, admission to the intensive care unit is generally recommended. Before delivery, maternal stabilization should be achieved 
before delivery, which includes airway management, treatment of hypertension, and correction of hypoglycemia, electrolyte and coagulation abnormalities. Careful maintenance of intravenous fluids and blood products, as well as frequent maternal vital signs assessment, and evaluation of changes in mental status are all crucial. Furthermore, frequent fetal assessment is also needed. Therefore, collaboration among different specialties such as intensive care, gastroenterology and perinatology are essential.

Once the mother is stabilized, delivery of the fetus is the next step. Vaginal birth is probably the best approach if tolerated; however, caesarean birth is often performed because of rapidly deteriorating maternal-fetal status. During the postpartum recovery period, hemodynamic monitoring is necessary because patients with AFLP are at high risk of bleeding as a result of coagulopathy. Transfusion of fluids and blood products may be needed. Besides risk of bleeding, patients are also at risk of hypoglycemia and glucose infusion may be needed. Lastly, one should not overlook other potential complications of AFLP (ie, pancreatitis), which usually develop after the onset of hepatic and renal dysfunction (24). The development of pseudocysts with secondary infections or hemorrhagic pancreatitis with resultant retroperitoneal bleeding can be difficult to control, especially when patient has coagulopathy. Thus, it may be worthwhile to do serial screening of serum lipase and amylase for several days after the onset of hepatic dysfunction. Imaging studies such as computed tomography or magnetic resonance imaging may be useful in assessing the development of pseudocysts or hemorrhagic pancreatitis.

Liver transplantation has rarely been performed for AFLP. A recent review of the American United Network for Organ Sharing (UNOS) database for the HELLP syndrome revealed that during the 16-year period between 1987 and 2003, there were only eight liver transplants performed for this pregnancyassociated condition (25). In their case report, Ockner et al (26) described a 35-year-old woman whose multisystem failure was rapidly reversed after liver transplantation. Therefore, they suggested that orthotopic liver transplantation should be considered for those women with fulminant hepatic failure due to AFLP, who manifest signs of irreversible liver failure despite delivery and aggressive supportive care. Similarly, Pereira et al (27) recommended that liver transplantation should be reserved for those patients with hepatic encephalopathy, severe metabolic acidosis or worsening coagulopathy, or those with liver rupture complicated by hepatic necrosis as indicated by computed tomography.

\section{ETIOLOGY}

Recent molecular advances suggest that AFLP may be a result of mitochondrial dysfunction (17). The process of mitochondrial fatty acid beta-oxidation consists of a series of transport steps and four enzymatic reactions. Normally, special carrier transporters transport fatty acids to the mitochondrial inner membrane, where they are then broken down by four enzymes. This pathway generates energy from free fatty acids for the brain, heart, liver and skeletal muscle during fasting, when the glycogen stores are depleted. Deficiency of the third enzyme, long-chain 3-hydroxyacyl-CoA dehydrogenase (LCHAD) results in accumulation of medium- and long-chain fatty acids. It is an autosomal recessive disorder and the heterozygous LCHAD deficiency has been identified in some women with AFLP (28).
In 1991, Schoeman et al (29) reported the association between recurrent AFLP cases and LCHAD defect, suggesting that affected women might have an inherited enzyme deficiency in beta-oxidation, predisposing them to AFLP. In 1993 and 1994, respectively, Wilcken et al (30) and Treem et al (31) reported six families of children with LCHAD deficiency; all had been born to mothers who suffered from AFLP or HELLP syndrome during pregnancy. Further retrospectives studies by Ibdah et al (32) also showed an association between LCHAD deficiency and AFLP.

In 1995, the gene for LCHAD was isolated, and genetic mutations associated with this deficiency were identified. The most common mutation occurs in the alpha-unit of the trifunctional protein gene $(1528 \mathrm{G} \rightarrow \mathrm{C})$, which alters amino acid 474 from glutamic acid to glutamine (E474Q), replacing the acidic and negatively charged side chain with a neutral, amidecontaining residue. This mutation is associated with approximately $65 \%$ to $90 \%$ of the LCHAD-deficient patients (33). The precise mechanism by which LCHAD deficiency in a fetus causes severe liver disease in mother is unclear. It is hypothesized because the mutation is recessive, under normal physiological conditions the mother does not have abnormal fatty acid oxidation. However, when both parents are heterozygous for this abnormality and the fetus acquires both of these mutations, the fetus will be unable to oxidize long-chain fatty acids. The unmetabolized free fatty acids return via the placenta to the mother's circulation, which strains maternal hepatic activity and overwhelms any diminished maternal hepatic enzyme activity, resulting in the symptoms of AFLP (34). Delivery of the infant eliminates the metabolic hepatic stress for the mother and perhaps explains why the fatty acid oxidation eventually normalizes postpartum (35).

This hypothesis, however, is not unequivocally accepted, as some investigators have not been able to confirm the association between AFLP and LCHAD deficiency (36). One possible explanation is that although there are a number of mutations leading to LCHAD deficiency, only specific genetic defects will lead to an increased risk of AFLP. Ibdah et al (32) evaluated 24 children with LCHAD deficiency; 19 of them were either homozygotes for a mutation in which glutamic acid was replaced with glutamine (E474Q) or compound heterozygotes (glumtamine mutation plus a different mutation on the other allele). Fifteen mothers of these children (79\%) had AFLP or HELLP, or both. On the other hand, pregnancy-related liver disease was not seen during pregnancies in children who had other mutations or had at least one wild-type allele (31). In a relatively recent cohort study by Yang et al (37), the number of children with LCHAD deficiency born to mothers with AFLP was estimated to be between $15 \%$ and $20 \%$ of all AFLP. complicated pregancies. On the other hand, only less than $2 \%$ of HELLP-complicated pregnancies are associated with fetal LCHAD deficiency with the G1528C on one or both alleles $(37,38)$.

What is the impact of LCHAD deficiency in infants? The toxic products of LCHAD deficiency accumulate in the mitochondria and can cause degeneration and fatty infiltration of muscle fibres $(39,40)$. This affects both skeletal and cardiac muscle development. The liver becomes enlarged with lipid depositions within the hepatocytes. There may be progressive jaundice associated with impaired bilirubin metabolism. Inherited LCHAD deficiency usually presents clinically in the neonatal period or in early childhood, frequently after a period 
of fasting or viral illness. At the time of diagnosis, infants frequently have severe liver failure, severe cardiomyopathy and hypoketotic hypoglycemic encephalopathy (31). These symptoms may be difficult to reverse. Typically, a diet low in long-chain fatty acids and supplemented with medium-chain triglycerides is recommended (35). Dietary therapy may improve long-term prognosis, although it has not been successful in preventing irreversible ophthalmological changes such as pigmentation of the fundus of the eye.

LCHAD deficiency can be suddenly lethal as well, especially when the infants experience an illness with associated fasting or vomiting, which make them metabolically reliant upon gluconeogenesis by lipid metabolism. Because of the severe complications from LCHAD deficiency, molecular testing for this deficiency should be performed in infants as well as in affected mothers and fathers $(41,42)$. Although there are a number of mutations for LCHAD deficiency, testing only for E474Q might be sufficient because fetuses of affected mothers almost always have the E474Q mutation on at least one allele.

\section{PATHOPHYSIOLOGY}

In AFLP, there is a progressive lipid accumulation within the hepatocytes. The normal fat content of the liver is approximately $5 \%$. In women with AFLP, this percentage can range from $13 \%$ to $19 \%$ (1). This fat accumulation, along with ammonia production by the hepatocytes, leads to eventual coaguloapthy and hypoglycemia secondary to evolving hepatic failure $(3,7)$. The liver is usually noted to be small, soft and yellow, most probably as a result of hepatocytolysis and atrophy of the liver cells (1). Furthermore, the kidney, pancreas, brain and bone marrow may also demonstrate microvesicular fat infiltration (7).

\section{RISK FACTORS}

As discussed above, deficiency of the enzyme LCHAD seems to predispose women to AFLP. Besides LCHAD deficiency, other clinical characteristics of pregnancy have also been identified as potential risk factors: primigravidas (first pregnancy), pre-eclampsia, male fetus and multiple gestation $(1,4)$. However, there is no causal relationship identified between these potential risk factors and AFLP as yet (10). There is one hypothesis that multiple gestations may place women at increased risk for AFLP because there is an increased production of fatty acid metabolites by more than one fetus (43). Ethnicity does not seem to be associated with AFLP. Drugs have also been proposed to be associated with AFLP and there is one case report (44) reporting the association between the use of acetylsalicylic acid and AFLP. The hypothesis is that nonsteroidal anti-inflammatory drugs, including salicylates, have been shown to inhibit trifunctional protein and, thus, long-chain fatty acid oxidation in mitochondria, which may precipitate the development of AFLP in a heterozygous (for LCHAD mutation) mother carrying a homozygous fetus (44).

\section{OUTCOMES}

\section{Maternal outcomes}

As mentioned previously, the mortality from AFLP is approximately $18 \%$ and deaths are usually secondary to sepsis, renal failure, circulatory collapse, pancreatitis or gastrointestinal bleeding (45). Among those who survived, the liver function tests may have shown continued deterioration for up to one week postpartum but then slowly recover.
Similarly, on computed tomography, the liver volume will also decrease and recover some time postpartum (16). The resolution of the disease is indicated by the initial improvement of hepatic dysfunction. Liver enzymes, ammonia and coagulation studies will begin to normalize and will be followed by a decrease in serum creatinine, as long as there is no permanent renal damage (23). Full clinical recovery usually occurs in several weeks with no long-term sequelae, although histological changes in the liver may persist for months (1).

Recurrence of AFLP in subsequent pregnancies can occur. Although the theoretical recurrence risk in subsequent pregnancies is $25 \%$ with a mother carrying a homozygous mutant or compound heterozygous fetuses, it is uncommon and only a few cases have been documented $(5,34,46-49)$. However, this may be an under-representation, because many women may refrain from having further pregnancies after the first occurrence. Therefore, affected women should still be informed, counselled and tested, along with their infants who may be affected, for LCHAD deficiency. If the patient decides to be pregnant again, she should be closely monitored for any early signs of acute fatty liver.

\section{Fetal outcomes}

In the past, the neonatal mortality rate had been estimated to be as high as $85 \%$; however, with prompt recognition and treatment, the mortality rate has dramatically decreased to approximately 23\% (50). Although the perinatal survival rate has improved, evidence of fetal compromise is not uncommon and can be present even while the mother is clinically stable. The reasons for increased fetal distress and neonatal death in the absence of maternal clinical decompensation is not very clear. However, this could be related to the need for expedited, premature delivery. Therefore, close fetal surveillance and neonatal care are essential.

\section{CONCLUSION}

AFLP is an uncommon, life-threatening disorder developing in the third trimester of pregnancy or early postpartum period. Early diagnosis sometimes can be difficult because AFLP shares features with other common disorders such as pre-eclampsia, viral hepatitis or cholestasis of pregnancy. However, careful history and physical examination, in conjunction with compatible laboratory and imaging results, are often sufficient to make the diagnosis, and liver biopsy is rarely indicated. Prompt delivery of the infant and intensive supportive care remain as the mainstay treatment for AFLP.

\section{REFERENCES}

1. Sheehan HL. The pathology of acute yellow atrophy and delayed chloroform poisoning. J Obstet Gynaecol Br Emp 1940;47:49-62.

2. Watson WJ, Seeds JW. Acute fatty liver of pregnancy. Obstet Gynecol Surv 1990;45:585-91.

3. Varner M, Rinderknecht NK. Acute fatty metamorphosis of pregnancy. A maternal mortality and literature review. J Reprod Med 1980;24:177-80.

4. Kaplan MM. Acute fatty liver of pregnancy. N Engl J Med 1985;313:367-70.

5. Knox TA, Olans LB. Liver disease in pregnancy. N Engl J Med 1996;335:569-76.

6. Riely CA. Acute fatty liver of pregnancy. Semin Liver Dis 1987;7:47-54.

7. McNulty J. Acute fatty liver of pregnancy. In: Foley MR, Strong TH, Garite TJ, eds. Obstetric Intensive Care Manual, 2nd edn. New York: The McGraw-Hill Companies Inc, 2004:207-15. 
8. Jwayyed SM, Blanda M, Kubina M. Acute fatty liver of pregnancy. J Emerg Med 1999;17:673-7.

9. Monga M, Katz AR. Acute fatty liver in the second trimester. Obstet Gynecol 1999;93:811-3.

10. Simpson KR, Luppi CJ, O'Brien-Abel N. Acute fatty liver of pregnancy. J Perinat Neonatal Nurs 1998;11:35-46.

11. Kennedy S, Hall PM, Seymour A, Hague WE. Transient diabetes insipidus and acute fatty liver of pregnancy. Br J Obstet Gynaecol 1994;101:387-91.

12. Tucker ED, Calhoun BC, Thorneycroft IH, Edwards MS. Diabetes insipidus and acute fatty liver: A case report. J Reprod Med 1993;38:835-8

13. Woll PJ, Record CO. Lactate elimination in man: Effects of lactate concentration and hepatic dysfunction. Eur J Clin Invest 1979;9:397-404.

14. Werner CJ, Zoller DP, Baskin WN, Eichmann RE. Acute fatty liver of pregnancy associated with maternal and fetal metabolic acidosis. J Fam Pract 1988;26:198-9.

15. Usta IM, Barton JR, Amon EA, Gonzalez A, Sibai BM. Acute fatty liver of pregnancy: An experience in the diagnosis and management of fourteen cases. Am J Obstet Gynecol 1994;171:1342-7.

16. Riely CA, Latham PS, Romero R, Duffy TP. Acute fatty liver of pregnancy. A reassessment based on observations in nine patients. Ann Intern Med. 1987;106:703-6.

17. Rahman TM, Wendon J. Severe hepatic dysfunction in pregnancy. QJM 2002;95:343-57.

18. Schorr-Lesnick B, Lebovics E, Dworkin B, Rosenthal WS. Liver diseases unique to pregnancy. Am J Gastroenterol 1991;86:659-70.

19. Campillo B, Bernuau J, Witz MO, et al. Ultrasonography in acute fatty liver of pregnancy. Ann Intern Med 1986;105:383-4.

20. Ober WB, Lecompte PM. Acute fatty metamorphosis of the liver associated with pregnancy; a distinctive lesion. Am J Med 1955;19:743-58.

21. Castro MA, Goodwin TM, Shaw KJ, Ouzounian JG, McGehee WG. Disseminated intravascular coagulation and antithrombin III depression in acute fatty liver of pregnancy. Am J Obstet Gynecol 1996;174:211-6.

22. Vigil-De Gracia P, Lavergne JA. Acute fatty liver of pregnancy. Int J Gynaecol Obstet 2001;72:193-5.

23. Rolfes DB, Ishak KG. Acute fatty liver of pregnancy: A clinicopathologic study of 35 cases. Hepatology 1985;5:1149-58.

24. Moldenhauer JS, O'brien JM, Barton JR, Sibai B. Acute fatty liver of pregnancy associated with pancreatitis: A life-threatening complication. Am J Obstet Gynecol 2004;190:502-5.

25. United Network for Organ Sharing. <www.unos.org> (Version current at September 8, 2005).

26. Ockner SA, Brunt EM, Cohn SM, Krul ES, Hanto DW, Peters MG. Fulminant hepatic failure caused by acute fatty liver of pregnancy treated by orthotopic liver transplantation. Hepatology 1990;11:59-64.

27. Pereira SP, O'Donohue J, Wendon J, Williams R. Maternal and perinatal outcome in severe pregnancy-related liver disease. Hepatology 1997;26:1258-62.

28. Wanders RJ, Vreken P, den Boer ME, Wijburg FA, van Gennip AH, IJlst L. Disorders of mitochondrial fatty acyl-CoA beta-oxidation. J Inherit Metab Dis 1999;22:442-87.

29. Schoeman MN, Batey RG, Wilcken B. Recurrent acute fatty liver of pregnancy associated with a fatty-acid oxidation defect in the offspring. Gastroenterology 1991;100544-8.

30. Wilcken B, Leung KC, Hammond J, Kamath R, Leonard JV. Pregnancy and fetal long-chain 3-hydroxyacyl coenzyme A dehydrogenase deficiency. Lancet 1993;341:407-8.

31. Treem WR, Rinaldo P, Hale DE, et al. Acute fatty liver of pregnancy and long-chain 3-hydroxyacyl-coenzyme A dehydrogenase deficiency. Hepatology 1994;19:339-45.

32. Ibdah JA, Bennett MJ, Rinaldo P, et al. A fetal fatty-acid oxidation disorder as a cause of liver disease in pregnant woman. $\mathrm{N}$ Engl J Med 1999;340:1723-31.

33. IJlst L, Oostheim W, Ruiter JP, Wanders RJ. Molecular basis of long-chain 3-hydroxyacyl-CoA dehydrogenase deficiency: Identification of two new mutations. J Inherit Metab Dis 1997;20:420-2.

34. Tein I. Metabolic disease in the fetus predisposes to maternal hepatic complications of pregnancy. Pediatr Res 2000;47:6-8.

35. Bellig LL. Maternal acute fatty liver of pregnancy and the associated risk for long-chain 3-hydroxyacyl-coenzyme a dehydrogenase (LCHAD) deficiency in infants. Adv Neonatal Care 2004:4:26-32.

36. Mansouri A, Fromenty B, Durand F, Degott C, Bernuau J, Pessayre D. Assessment of the prevalence of genetic metabolic defects in acute fatty liver of pregnancy. J Hepatol 1996;25:781.

37. Yang Z, Yamada J, Zhao Y, Strauss AW, Ibdah JA. Prospective screening for pediatric mitochondrial trifunctional protein defects in pregnancies complicated by liver disease. JAMA 2002;288:2163-6.

38. Ibdah JA, Yang Z, Bennett MJ. Liver disease in pregnancy and fetal fatty acid oxidation defects. Mol Genet Metab 2000;71:182-9.

39. Tyni T, Majander A, Kalimo H, Rapola J, Pihko H. Pathology of skeletal muscle and impaired respiratory chain function in longchain 3-hydroxyacyl-CoA dehydrogenase deficiency with the G1528C mutation. Neuromuscul Disord 1996;6:327-37.

40. Tyni T, Rapola J, Paetau A, Palotie A, Pihko H. Pathology of longchain 3-hydroxyacyl-CoA dehydrogenase deficiency caused by the G1528C mutation. Pediatr Pathol Lab Med 1997;17:427-47.

41. Sims HF, Brackett JC, Powell CK, et al. The molecular basis of pediatric long chain 3-hydroxyacyl-CoA dehydrogenase deficiency associated with maternal acute fatty liver of pregnancy. Proc Natl Acad Sci 1995;92:841-5.

42. Isaacs JD Jr, Sims HF, Powell CK, et al. Maternal acute fatty liver of pregnancy associated with fetal trifunctional protein deficiency: Molecular characterization of a novel maternal mutant allele. Pediatr Res 1996;40:393-8.

43. Davidson KM, Simpson LL, Knox TA, D'Alton ME. Acute fatty liver of pregnancy in triplet gestation. Obstet Gynecol 1998;91:806-8.

44. Saygan-Karamursel B, Kizilkilic-Parlakgumus A, Deren O, Onderoglu L, Durukan T. Acute fatty liver of pregnancy after aspirin intake. J Matern Fetal Neonatal Med 2004;16:65-6.

45. Ranjan V, Smith NC. Acute fatty liver of pregnancy. J Obstet Gynaecol 1997;17:285-6.

46. Reyes H, Sandoval L, Wainstein A, et al. Acute fatty liver of pregnancy: A clinical study of 12 episodes in 11 patients. Gut 1994;35:101-6.

47. MacLean MA, Cameron AD, Cumming GP, Murphy K, Mills P, Hilan KJ. Recurrence of acute fatty liver of pregnancy. Br J Obstet Gynaecol 1994;101:453-4.

48. Zurcher K. [Uncomplicated second pregnancy following acute fatty liver of pregnancy]. Schweiz Med Wochenschr 1995;125:1003-5.

49. Bacq Y, Riely CA. Acute fatty liver of pregnancy: The hepatologist's view. Gastroenterologist 1993;1:257-64.

50. Fesenmeier MF, Coppage KH, Lambers DS, Barton JR, Sibai BM. Acute fatty liver of pregnancy in 3 tertiary care centers. Am J Obstet Gynecol 2005;192:1416-9. 


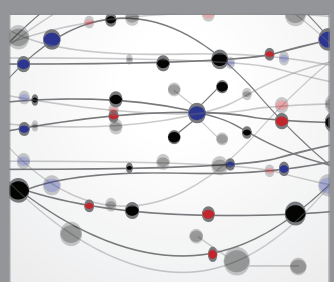

The Scientific World Journal
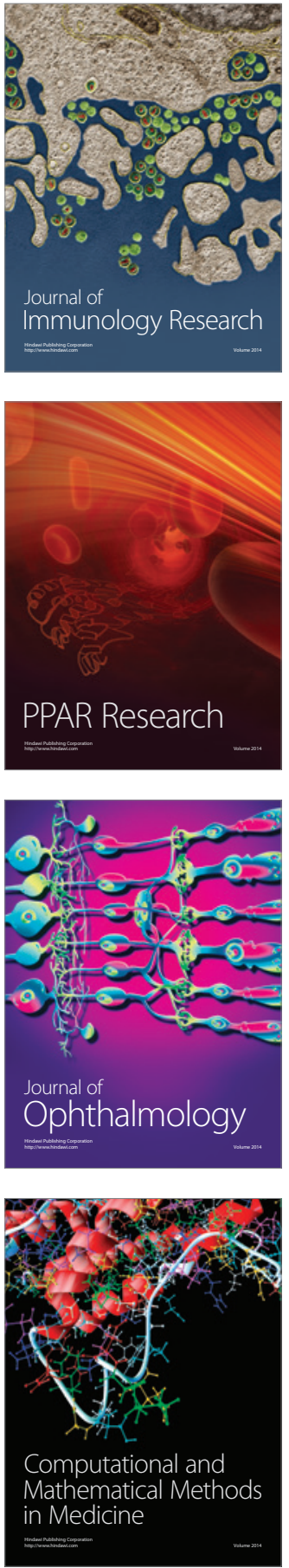

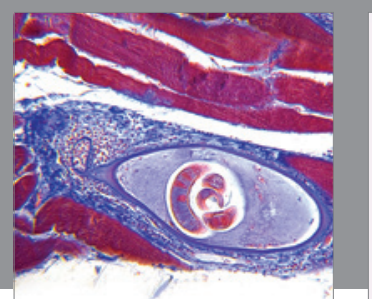

Gastroenterology Research and Practice

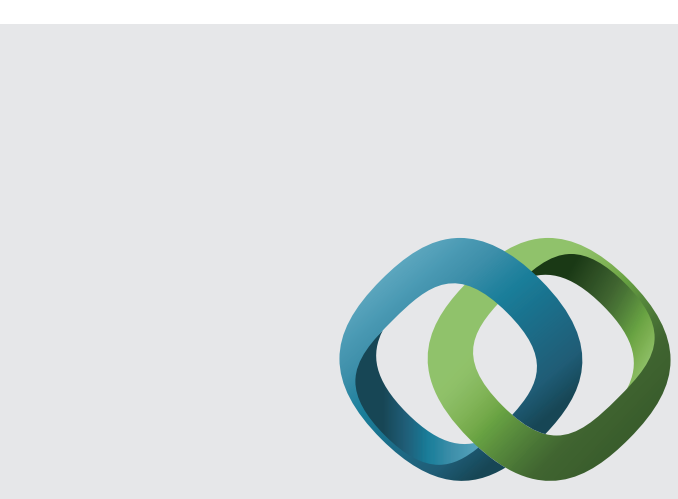

\section{Hindawi}

Submit your manuscripts at

http://www.hindawi.com
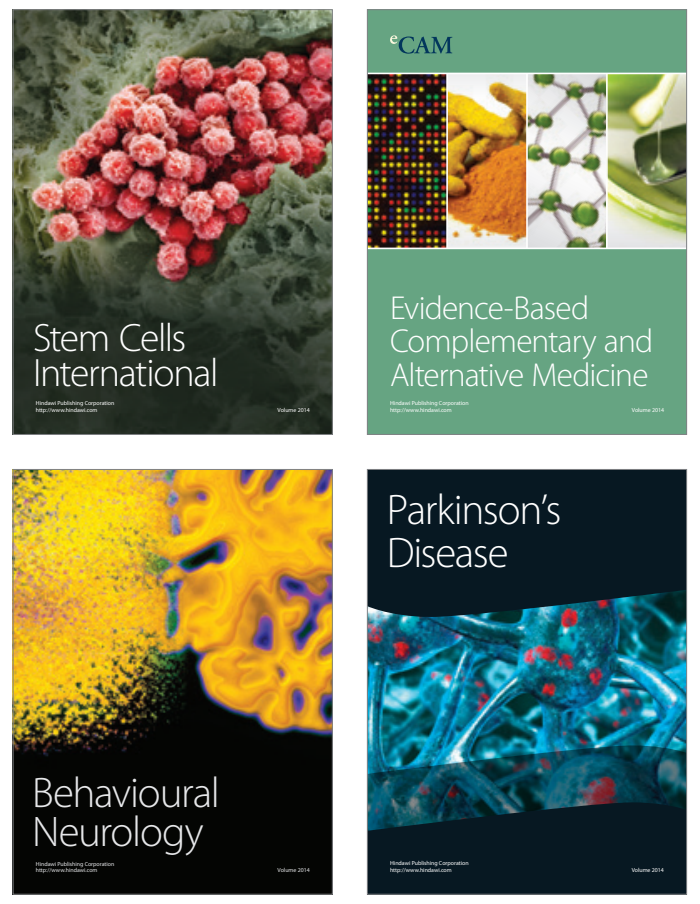
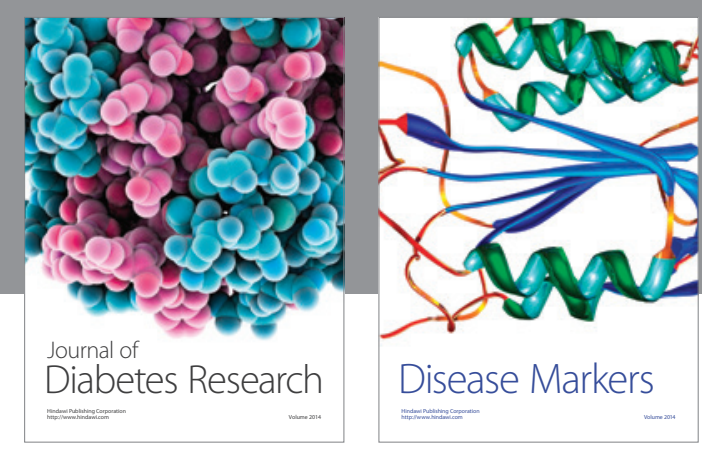

Disease Markers
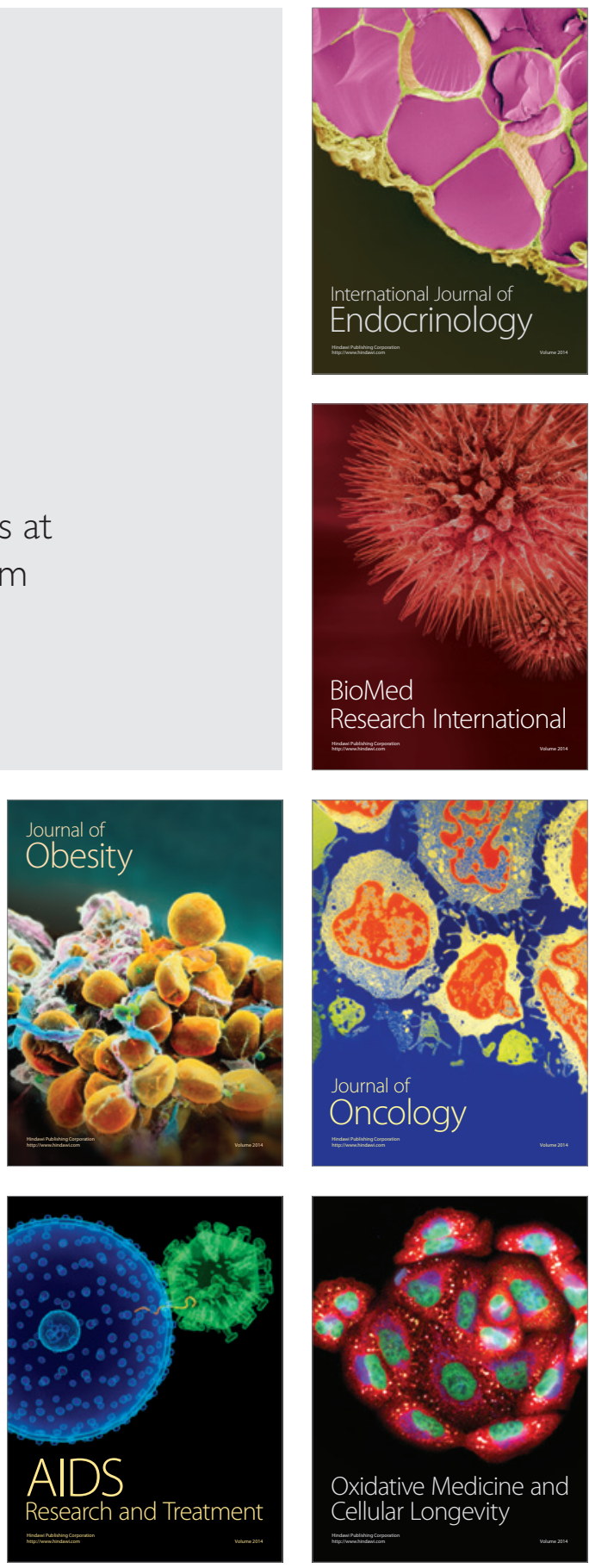